\title{
Rough Set Model for Nutrition Management in Site Specific Rice Growing Areas
}

\author{
K. Lavanya, N.Ch.S.N. Iyengar, M.A. Saleem Durai \\ School of Computing Science and Engineering, VIT University, Vellore, India \\ Email: lavanya.sendhilvel@gmail.com,nchsniyengar48@gmail.com,masaleemdurai@vit.ac.in
}

T. Raguchander

Tamilnadu Agricultural University, Coimbatore, India

Email: raguchander@ rediffmail.com

\begin{abstract}
The optimized fertilizer usage for better yield of rice cultivation is influenced by key factors like soil fertility, crop variety, duration, season, nutrient content of the fertilizer, time of application etc., It is observed that 60 percent of yield gap in tamilnadu is due to farmers lack of knowledge on key factors and informal sources of information by pesticide dealers. In this study the major contributing factors for fertilizer requirement and optimum crop yield were analyzed based on rough set theory. In data analytics perspective the nutrient plan is sort of multiple attribute decision-making processes. To reduce the complexity of decision making, key factors that are indiscernible to conclusion are eliminated. Our rough set based approach improved the quality of agricultural data through removal of missing and redundant attributes. After pretreatment the data formed as target information, then attribute reduction algorithm was used to derive rules. The generated rules were used to structure the nutrition management decision-making. The precision was above $88 \%$ and experiments proved the feasibility of the developed decision support system for nutrient management.
\end{abstract}

Index Terms- Rough Set, Attribute Reduction, NPK Supplies

\section{INTRODUCTION}

Indian paddy cultivation generates a direct or indirect economic livelihood for over $75 \%$ of the population .In tamilnadu, rice acreage cultivation is about 19.057 lakh hectares (Directorate of Rice Development, 2010-11). The average yield of rice is about $3040 \mathrm{~kg} / \mathrm{ha}$. The suitable season for cost-effective cultivation is kahrif and rabi. The general fertilizer recommendation for irrigated crops is $150-50-50 \mathrm{~kg} \mathrm{NPK} / \mathrm{ha}$ and blanket recommendation for rain-fed crops is 50:25:25 kg NPK/ha (Department of Agriculture, 2012). However most of the farmers in irrigated areas apply excessive amount of fertilizer especially nitrogen fertilizer of 175 $200 \mathrm{~kg} \mathrm{~N} / \mathrm{ha}$ [2] which is considerably higher than the government recommendation. This unwanted investment plays vital role for the yield gap, degradation of soil fertility and postharvest loss.

The growth and development of fertilizer optimization [3] lead to acquisition of numerous key features and its storage in databases. Considering the entire features may slow down the learning process and may reduce the performance of the classifier because of redundant and irrelevant features. Many methods were proposed to mine rules for the growing data. Most of the tools of knowledge min ing are crisp, traditional, determin istic and precise in notion. Real situations are very often the reverse of it. The detailed description of the real system needs detailed data which is beyond recognition of the human interpretation. This invoked an extension of the concept of crisp sets to model imprecise, mixed type, incomplete data and enables their modeling intellects.

Rough set theory proposed by pawlak in 1982, is used to study [5] mixed types of data such as continuous, valued and symbolic data. It acts as a knowledge discovery tool that helps to induce logical patterns hidden in massive data. It combines both qualitative and quantitative data in decision making. Rough set analyzes attributes with real values and categorizes the attribute's value into intervals. These categorical data are subjected to attribute reduction and rule generation [7] that can be used for both key factors selection and knowledge discovery. It helps us to find out the minimal rule sets called reducts to classify objects without deterioration of classification quality and induce minimal length decision rules inherent in the given information system.

In our study, the supporting factors for paddy cultivation are selected from the collected data as conditional attributes and the amount of N, P, K(Nitrogen, Potassium, Sodium) supplies is considered as the decision attribute. As preprocessing these attribute values are mapped on to domain values and coded as numerical (eg. low (1), medium (2), high (3)). Then the lower and upper approximations of elementary sets (the set of objects with the same decision attribute value) are computed. With the help of the proposed algorithm, decision rules are generated by attribute reduction and iterations. Then the decision rules are validated against the threshold value and formu lated as a base for nutrition management. Thus we make an attempt to analyze the supporting growth factors and formalize the approximate N,P,K supplement values needed for site specific crops.

The structure of paper is organized as follows. Section II, III highlights the background and basic study respectively. Proposed System is presented in Section IV and evaluation of the proposed system is discussed in Section VI. 


\section{RELATED WORKS}

Various methodologies used for knowledge discovery are reviewed in this section. The rule reduction [11] can be treated effectively by means of learning premises generalized by genetic algorithm (GA) rather than enumerating AND-connection of input fuzzy sets. The computational efficiency of minimum reducts [12] is highly improved by counting the distinct rows of the subdecision table, instead of generating discernibility functions or the positive regions. The use of entropy in fuzzy-rough feature selection can result in smaller subset sizes than those obtained through FRFS [15] alone, with little loss or even an increase in overall classification accuracy. The Genetic programming [16] is used to construct new features of the data that gives consideration to hide relationships between features. The Particle swarms find optimal regions of the complex search space through the interaction of individuals in the population. PSO is attractive [17] for feature selection and discovers best feature combinations as they fly within the subset space. A new feature called maximum information compression index is generic in nature and has the capability of multi scale representation of data sets. The superiority of the algorithm in terms of speed and performance is established extensively over various reallife data sets of different sizes and dimensions. It is also demonstrated how redundancy [18] and information loss in feature selection can be quantified with an entropy measure . $\alpha$-Torrent rough set theory is applied to the field of remote sensing classification. The classifier can adapt to the spatial date with severe overlapped features. The experiments results are compared with PCA and traditional rough set[21] this method produces usefully features and improved classification accuracy. The fuzzy rules increase deals with the data pairs contain noise or outlier. The Fuzzy-rough feature selection is introduced for fuzzy rules reduction. To achieve good performance [22] the parameters of fuzzy predictor of every fu zzy rule will be adjusted by learning algorithm. Three novel feature selection techniques employing fuzzy entropy to locate fuzzy-rough reducts is applied. This approach is compared with two other fuzzy-rough feature selection [23] approaches which utilize other measures for the selection of subsets. A rough set reduction scheme for Support Vector Machine (SVM) is used for the classification task [24] based on the significance of each feature vector, while the rough set is applied to improve feature selection and data reduction.

\section{BASIC CONCEPTS OF ROUGH SET THEORY}

\section{A. Rough Set}

Rough set is a formal approximation [1] of a crisp set (i.e., conventional set) in terms of a pair of sets which give the lower and the upper approximation of the original set.

\section{B. Information System}

Given $(\mathrm{U}, \mathrm{A})$ be an information system where $\mathrm{U}$ be the finite non empty set (universe) of objects and A is nonempty finite set of attributes (features, variables).For every a $\varepsilon \mathrm{A}, \mathrm{V}_{\mathrm{a}}$ is the set of values attribute a may take, called domain of attribute $A$.

In addition every attribute a $\varepsilon$ A defines an in formation function, $\mathrm{D}_{\mathrm{a}}: \mathrm{U} \rightarrow \mathrm{V}$

From table 1,

$$
\begin{aligned}
& U=\{x 1, x 2, x 3, x 4, x 5, x 6 \ldots \ldots \ldots . . . x 10\} \\
& A=\{a 1, a 2, d\}
\end{aligned}
$$

The domains of attributes are

$$
\begin{aligned}
& \text { V1 }(\text { for a1) }=\{1,2\} \\
& \text { V2 }(\text { for a2) }=\{1,2,3\} \\
& \text { V3 }(\text { for } d)=\{1,2\}
\end{aligned}
$$

Table 1. Coded Information Table

\begin{tabular}{|c|c|c|c|}
\hline $\mathrm{U}$ & $\mathrm{a} 1$ & $\mathrm{a} 2$ & $\mathrm{~d}$ \\
\hline $\mathrm{X} 1$ & 1 & 1 & 2 \\
\hline $\mathrm{X} 2$ & 1 & 2 & 1 \\
\hline $\mathrm{X} 3$ & 1 & 3 & 1 \\
\hline $\mathrm{X} 4$ & 2 & 1 & 2 \\
\hline $\mathrm{X} 5$ & 2 & 2 & 2 \\
\hline $\mathrm{X} 6$ & 2 & 3 & 1 \\
\hline $\mathrm{X} 7$ & 2 & 2 & 1 \\
\hline $\mathrm{X} 8$ & 2 & 3 & 2 \\
\hline
\end{tabular}

\section{Indiscernibility Relation}

Two objects $x_{i}, x_{j}$ are said to be indiscernible by their set of attributes $B$ where $B \varepsilon A$, if $b\left(x_{i}\right)=b\left(x_{j}\right)$ ie., every element in the subset $B$ must be equal. It is generally represented as $\operatorname{Ind}(\mathrm{B})$. Every subset in $\operatorname{Ind}(\mathrm{B})$ is known as elementary set in $B$ because it is the smallest indiscernible group of objects

Table 2. Equivalence Classes

\begin{tabular}{|c|c|c|}
\hline U/A & a1 & a2 \\
\hline$\{x 5, x 7\}$ & 2 & 2 \\
\hline$\{x 6, x 8\}$ & 2 & 3 \\
\hline$\{x 1\}$ & 1 & 1 \\
\hline$\{\mathrm{x} 2\}$ & 1 & 2 \\
\hline$\{x 3\}$ & 1 & 3 \\
\hline$\{x 4\}$ & 2 & 1 \\
\hline
\end{tabular}

Each row in the table 2 represents an elementary set for the information system studied. U/A represents the elementary sets in space $A\{a 1, a 2\}$ ie. For instance we are interested in two attributes only.

\section{Lower and Upper Approximations}

For data analysis rough set approach defines two basic concepts namely the lower and the upper approximations of a set. The lower approximation of the set $\mathrm{X}$ is a set of objects $\mathrm{x}_{\mathrm{i}}$, belonging to the elementary sets contained in $\mathrm{X}$ (of space $\mathrm{R}$ ) 


$$
\underline{R} X=\bigcup\{Y \in U / R: Y \subseteq X\}
$$

The upper approximation is the union of elementary sets with a non empty intersection to $\mathrm{X}$.

$$
\bar{R} X=\bigcup\{Y \in U / R: Y \cap X \neq \phi\}
$$

The $R$-boundary of $X, B N_{R}(X)$ is given by $B N_{R}(X)=\bar{R} X-\underline{R} X$. We say $X$ is rough with respect to $R$ if and only if $\bar{R} X \neq \underline{R} X$, equivalently $B N_{R}(\mathrm{X}) \neq \phi . X$ is said to be $R$-definable if and only if $\bar{R} X=\underline{R} X$ or $B N_{R}(X)=\phi$. So, a set is rough with respect to $R$ if and only if it is not $R$ definable

Table 3. Discernibility Matrix

\begin{tabular}{|c|c|c|c|c|c|c|c|}
\hline U & X1 & X2 & X3 & X4 & X5 & X6 & X7 \\
\hline X2 & $\mathrm{a} 2$ & & & & & & \\
\hline X3 & $\mathrm{a} 2$ & $\mathrm{a} 2$ & & & & & \\
\hline X4 & $\mathrm{a} 1$ & $\mathrm{a} 1, \mathrm{a} 2$ & $\mathrm{a} 1, \mathrm{a} 2$ & & & & \\
\hline X5 & $\mathrm{a} 1$ & $\mathrm{a} 1$ & $\mathrm{a} 1, \mathrm{a} 2$ & $\mathrm{a} 2$ & & & \\
\hline X6 & $\mathrm{a} 2$ & $\mathrm{a} 1, \mathrm{a} 2$ & $\mathrm{a} 1$ & $\mathrm{a} 2$ & $\mathrm{a} 2$ & & \\
\hline $\mathrm{X} 7$ & $\mathrm{a} 1, \mathrm{a} 2$ & $\mathrm{a} 1$ & $\mathrm{a} 1, \mathrm{a} 2$ & $\mathrm{a} 2$ & $\mathrm{~d}$ & $\mathrm{a} 2$ & \\
\hline X8 & $\mathrm{a} 1, \mathrm{a} 2$ & $\mathrm{a} 1, \mathrm{a} 2$ & $\mathrm{a} 1$ & $\mathrm{a} 2$ & $\mathrm{a} 2$ & $\mathrm{~d}$ & $\mathrm{a} 2$ \\
\hline
\end{tabular}

\section{E. Accuracy of approximation}

For the attributes $P \subseteq \mathrm{A}$, we can measure accuracy for any set $X \subseteq U$ (i.e. $\left.\alpha_{\mathrm{A}}(X)\right)$ called the accuracy of approximation as follows:

$$
\alpha_{\mathrm{A}}(X)=\frac{\text { cardinality of } \overline{\mathrm{A}} X}{\text { cardinality of } \overline{\overline{\mathrm{A}}} X}=\frac{|\underline{\mathrm{A}} X|}{|\overline{\mathrm{A}} X|}
$$

Where $|\mathrm{X}|$ denotes the cardinality of Obviously

If $\alpha_{B}(X)=1 X$ is crisp with respect to $\mathrm{A}$.

If $\alpha_{B}(X)<1 X$ is rough with respect to $\mathrm{A}$

\section{F. Independence of attributes}

$$
I(P)=I(P-\{a\})
$$

If an attribute (a) re moval does not increase the number of basic elementary sets then it is a superfluous attribute. Else, attribute (a) is indispensable in space $P$.

$$
\operatorname{Ind}(\mathrm{A})=\operatorname{Ind}(\mathrm{A}-\mathrm{a} 1)
$$

The elementary sets after Ind(A-a1) are $\{\{x 1, x 4\},\{x 2, x 7\},\{x 3, x 6\},\{x 5\},\{x 8\}\}$ which are not same as basic elementary sets so attribute a1 is indispensable in A.

\section{G. Attribute Reduction and Rule Deduction}

A Decision table is comprised of a set of conditional attributes $\mathrm{A}$ and set of decision attributes D.

\section{1). D-Superflous attributes}

To find all possible minimal subsets of attributes, leading to a similar number of elementary sets as the whole set of attributes is reduct. To find the set of all dispensable attributes is core. To compute reduct and core the discernibility matrix is used of dimension $\mathrm{p} x \mathrm{p}$, where $\mathrm{p}$ is the no of elementary sets and its elements are the set of all attributes which discern elementary sets $\mathrm{x}_{\mathrm{i}}$ and $\mathrm{x}_{\mathrm{j}}$

\section{2). D-core and D-Reduct}

The set of all $D$-indispensable attributes in $A$ is called the $D$-core of $A$, whereas, the minimal subsets of condition attributes that discern all equivalence classes of the relation $\operatorname{Ind}(D)$ discernable by the entire set of attributes are called $D$-reducts. D-Core and D-reduct aims at removing unnecessary attributes in the decision table.

\section{3). $R$-core and R-reduct of attributes}

The R-reduct uses considerably modified discernibility matrix. An element of the $D$-discernibility matrix of $A$ is defined as the set of all attributes which discern the objects $x_{i}$ and $x_{j}$, which do not belong to the same equivalence class of the relation $\operatorname{Ind}(D)$, i.e., to the same class. The $D$-core is the set of all single elements of the $D$-discernibility matrix of $A$. D.Decision Rules deduction

The described decision table can also be regarded as a set of decision classification rules of the form $a_{k} i \rightarrow d_{j}$, which means that attribute ' $\mathrm{a}_{\mathrm{k}}$ ' (value 'i') leads to decision $d$ (value ' $j$ ') and ' $\rightarrow$ ' denotes propositional implication.

Table 4 . Decision Matrix

\begin{tabular}{|c|c|c|c|}
\hline $\mathrm{U}$ & $\mathrm{a} 1$ & $\mathrm{a} 2$ & $\mathrm{~d}$ \\
\hline $\mathrm{X} 1$ & 1 & $*$ & 2 \\
\hline $\mathrm{X} 2$ & 1 & 2 & 1 \\
\hline $\mathrm{X} 3$ & 1 & $*$ & 1 \\
\hline $\mathrm{X} 4$ & $*$ & 1 & 2 \\
\hline $\mathrm{X} 5$ & $*$ & 2 & 2 \\
\hline $\mathrm{X} 6$ & $*$ & 3 & 1 \\
\hline $\mathrm{X} 7$ & $*$ & 2 & 1 \\
\hline $\mathrm{X} 8$ & 2 & 3 & 2 \\
\hline
\end{tabular}

\section{PROPOSED MODEL}

The nutrient plan is sort of multiple attributes decisionmaking processes [9]. It is certain that we have to deal with massive data. Current technologies convert large volume of data into knowledge and use that knowledge to make a proper decision. However, it fails in many instances because the imprecise, uncertain information in the databases are not processed. Rough set theory describes and models the ill-defined data using indiscernibility relation without transforming the data. Our approach uses rough set to deal with complicated 
attribute aspects such as its importance, interrelations, dimensionality and varied patterns to acquire knowledge directly from data. This work utilizes rough set theory as a preprocessing step to reduce the redundant key factors and to improve the quality of knowledge content in data set. The resultant reduced rule sets from the algorithm serves as a knowledge database for rice nutrition management in site specific regions.

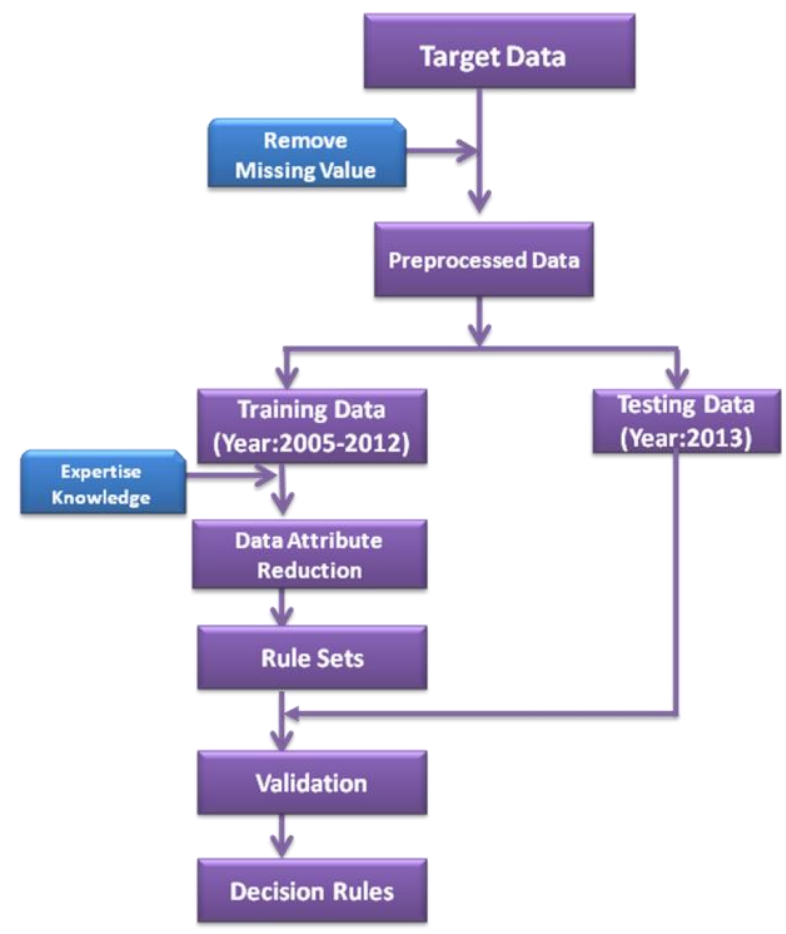

Fig. 1. Rough set based nutrition management

\section{Algorithm}

Input:

$\mathrm{D}$, a dataset consisting of training tuples and associated target values

Attr $=\{c, d\}$, set of attributes and possible values

c:set of conditional attributes;

$\mathrm{d}$ :set of decision attributes

min_sup: minimum support threshold

Output: Attribute reduction \& Rule Sets

1 .For each tuple in D

Repeat

Remove redundant \& irrelevant values

End For

2. Divide data in Training and Testing data

3. In Training data, construct discernibility matrix and reducts

4. While (support of reduct >= min_sup)

Perform attribute reduction and generate candidate rules

End While

5. Validation

The candidate rules are compared with every object in testing data set. The performance of every rule is computed by
Accuracy $=\frac{\text { Sum of supported rules pointing to decision } \mathrm{d}}{\text { Sum of supported and non }- \text { supported rules }}$ If

Accuracy exceeds min_sup conclude the validated rules as finalized rules

Else

Delete the rule

\section{Rough SET METHODOLOGY-AN ILLUSTRATIVE EXAMPLE}

Our study considers a target dataset of 32 elements. To ensure consistency and completeness unreliable and unrelated data were removed to avoid complexity. Data is described in terms of eight attributes based on problem domain. The attributes presented are of two types conditional attributes $\left(a_{1} \ldots a_{8}\right)$ and decision attribute (d). Using training dataset candidate rules are generated and are validated against testing dataset using support count and threshold.

Table 5. Target Data Set

\begin{tabular}{|c|c|c|c|c|c|c|c|c|c|}
\hline Objects & $\mathrm{a}_{1}$ & $\mathrm{a}_{2}$ & $\mathrm{a}_{3}$ & $\mathrm{a}_{4}$ & $\mathrm{a}_{5}$ & $\mathrm{a}_{6}$ & $\mathrm{a}_{7}$ & $\mathrm{a}_{8}$ & $\mathrm{~d}$ \\
\hline $\mathrm{O}_{1}$ & 3 & 4 & 3 & 1 & 4 & 1 & 2 & 1 & 4 \\
\hline $\mathrm{O}_{2}$ & 4 & 3 & 4 & 1 & 3 & 1 & 3 & 2 & 4 \\
\hline $\mathrm{O}_{3}$ & 2 & 4 & 3 & 2 & 3 & 1 & 2 & 2 & 3 \\
\hline $\mathrm{O}_{4}$ & 2 & 2 & 2 & 3 & 2 & 2 & 1 & 2 & 2 \\
\hline $\mathrm{O}_{5}$ & 2 & 2 & 2 & 2 & 2 & 1 & 1 & 2 & 2 \\
\hline $\mathrm{O}_{6}$ & 1 & 2 & 2 & 3 & 2 & 3 & 1 & 2 & 1 \\
\hline $\mathrm{O}_{7}$ & 1 & 2 & 2 & 3 & 2 & 2 & 2 & 2 & 2 \\
\hline $\mathrm{O}_{8}$ & 3 & 4 & 3 & 2 & 3 & 1 & 1 & 1 & 3 \\
\hline $\mathrm{O}_{9}$ & 4 & 4 & 3 & 2 & 4 & 1 & 3 & 1 & 4 \\
\hline $\mathrm{O}_{10}$ & 1 & 1 & 2 & 3 & 2 & 2 & 1 & 2 & 1 \\
\hline $\mathrm{O}_{11}$ & 1 & 2 & 2 & 3 & 2 & 1 & 1 & 2 & 2 \\
\hline $\mathrm{O}_{12}$ & 3 & 3 & 4 & 1 & 3 & 1 & 3 & 1 & 3 \\
\hline $\mathrm{O}_{13}$ & 2 & 3 & 4 & 1 & 4 & 1 & 4 & 1 & 4 \\
\hline $\mathrm{O}_{14}$ & 1 & 2 & 2 & 3 & 2 & 2 & 2 & 2 & 2 \\
\hline $\mathrm{O}_{15}$ & 2 & 1 & 1 & 4 & 1 & 3 & 2 & 2 & 1 \\
\hline $\mathrm{O}_{16}$ & 1 & 2 & 1 & 4 & 1 & 2 & 1 & 2 & 1 \\
\hline $\mathrm{O}_{17}$ & 3 & 4 & 4 & 3 & 4 & 1 & 1 & 1 & 4 \\
\hline $\mathrm{O}_{18}$ & 4 & 4 & 4 & 3 & 3 & 1 & 2 & 1 & 4 \\
\hline $\mathrm{O}_{19}$ & 2 & 3 & 3 & 2 & 2 & 2 & 1 & 2 & 2 \\
\hline $\mathrm{O}_{20}$ & 3 & 3 & 3 & 4 & 2 & 1 & 2 & 2 & 3 \\
\hline $\mathrm{O}_{21}$ & 1 & 2 & 2 & 2 & 1 & 3 & 1 & 3 & 1 \\
\hline $\mathrm{O}_{22}$ & 2 & 3 & 4 & 3 & 2 & 2 & 1 & 2 & 2 \\
\hline $\mathrm{O}_{23}$ & 1 & 4 & 2 & 1 & 4 & 1 & 3 & 3 & 1 \\
\hline $\mathrm{O}_{24}$ & 1 & 2 & 2 & 3 & 2 & 2 & 2 & 2 & 2 \\
\hline $\mathrm{O}_{25}$ & 1 & 2 & 2 & 3 & 2 & 3 & 1 & 2 & 1 \\
\hline $\mathrm{O}_{26}$ & 2 & 3 & 4 & 1 & 4 & 1 & 4 & 1 & 4 \\
\hline $\mathrm{O}_{27}$ & 3 & 4 & 3 & 1 & 4 & 1 & 2 & 1 & 4 \\
\hline $\mathrm{O}_{28}$ & 1 & 2 & 2 & 3 & 2 & 2 & 2 & 2 & 2 \\
\hline $\mathrm{O}_{29}$ & 4 & 4 & 4 & 3 & 3 & 1 & 2 & 1 & 4 \\
\hline $\mathrm{O}_{30}$ & 3 & 4 & 4 & 3 & 2 & 1 & 2 & 1 & 2 \\
\hline
\end{tabular}


we randomly subdivided the data set into 22 objects of training data and 10 objects of testing data. As per step 3 of proposed algorithm a set of reducts is generated from training data set along with support count (table 6). According to domain intelligence the minimu m threshold is $60 \%$, therefore rules 1,2 and 5 are selected whereas rule $3,4,6,7,8$ cannot be selected. Since the first, second and fifth rules are selected, we exclude the objects $\mathrm{O} 1, \mathrm{O}_{2}$, $\mathrm{O}_{3}, \mathrm{O}_{4}, \mathrm{O}_{5}, \mathrm{O}_{7}, \mathrm{O}_{9}, \mathrm{O}_{11}, \mathrm{O}_{13}, \mathrm{O}_{14}, \mathrm{O}_{17}, \mathrm{O}_{18}, \mathrm{O}_{19}, \mathrm{O}_{22}$ from the training data set.

Table 6. Reduct And Core [First Iteration]

\begin{tabular}{|c|c|c|c|c|c|c|c|c|l|}
\hline Rules & $\mathrm{a}_{1}$ & $\mathrm{a}_{2}$ & $\mathrm{a}_{3}$ & $\mathrm{a}_{4}$ & $\mathrm{a}_{5}$ & $\mathrm{a}_{7}$ & $\mathrm{a}_{8}$ & $\mathrm{~d}$ & \multicolumn{1}{|c|}{ Supporting Objects } \\
\hline$[1]$ & $\mathrm{x}$ & $\times$ & $\times$ & $\times$ & 1 & $\mathrm{x}$ & $\times$ & 1 & $\mathrm{O}_{15}, \mathrm{O}_{16}, \mathrm{O}_{21}$ \\
\hline$[2]$ & 1 & $\times$ & $\times$ & $\times$ & $\times$ & 1 & $\times$ & 1 & $\mathrm{O}_{6}, \mathrm{O}_{10}, \mathrm{O}_{16}, \mathrm{O}_{21}$ \\
\hline$[3]$ & 2 & $\mathrm{x}$ & $\times$ & 3 & 2 & $\times$ & $\times$ & 2 & $\mathrm{O}_{4}, \mathrm{O}_{5}, \mathrm{O}_{19}, \mathrm{O}_{22}$ \\
\hline$[4]$ & $\times$ & 2 & $\times$ & 3 & 2 & $\times$ & $\times$ & 2 & $\mathrm{O}_{4}, \mathrm{O}_{7}, \mathrm{O}_{11}, \mathrm{O}_{14}$ \\
\hline$[5]$ & 3 & $\times$ & $\times$ & $\times$ & 3 & $\times$ & $\times$ & 3 & $\mathrm{O}_{8}, \mathrm{O}_{12}, \mathrm{O}_{20}$ \\
\hline$[6]$ & 2 & $\times$ & $\times$ & $\times$ & 3 & $\mathrm{x}$ & $\times$ & 3 & $\mathrm{O}_{3}$ \\
\hline$[7]$ & $\times$ & $\mathrm{x}$ & $\times$ & $\times$ & 4 & $\times$ & $\times$ & 4 & $\mathrm{O}_{1}, \mathrm{O}_{9}, \mathrm{O}_{13}, \mathrm{O}_{17}$ \\
\hline$[8]$ & 4 & $\times$ & $\times$ & $\times$ & $\times$ & $\mathrm{x}$ & $\times$ & 4 & $\mathrm{O}_{2}, \mathrm{O}_{9}, \mathrm{O}_{18}$ \\
\hline
\end{tabular}

Since not all the decision rules are obtained, objects $\mathrm{O}_{6}, \mathrm{O}_{8}, \mathrm{O}_{9}, \mathrm{O}_{10}, \mathrm{O}_{12}, \mathrm{O}_{13}, \mathrm{O}_{15}, \mathrm{O}_{16}, \mathrm{O}_{17}, \mathrm{O}_{20}, \mathrm{O}_{21}$ (table 6) of rules 1,2 and 5 are taken into consideration for second iteration. Again step 3 is applied on attributes $a_{1}, a_{2} \ldots . a_{7}$ and candidate rules are generated along with supporting objects (table 7). Based on domain intelligence we select the first, second, fourth and fifth rules

Table 7. Reduct And Core [Second Iteration]

\begin{tabular}{|c|c|c|c|c|c|c|c|c|l|}
\hline Reduct & $\mathrm{a}_{1}$ & $\mathrm{a}_{2}$ & $\mathrm{a}_{3}$ & $\mathrm{a}_{4}$ & $\mathrm{a}_{5}$ & $\mathrm{a}_{7}$ & $\mathrm{a}_{8}$ & $\mathrm{~d}$ & supporting objects \\
\hline$[1]$ & 1 & $\times$ & $\times$ & $\times$ & $\times$ & $\times$ & $\times$ & 1 & $\mathrm{O}_{6}, \mathrm{O}_{19}, \mathrm{O}_{16}, \mathrm{O}_{21}$ \\
\hline$[2]$ & 2 & 2 & $\times$ & $\times$ & $\times$ & $\times$ & $\times$ & 2 & $\mathrm{O}_{5}$ \\
\hline$[3]$ & $\times$ & $\times$ & $\times$ & $\times$ & 3 & $\times$ & $\times$ & 3 & $\mathrm{O}_{8}, \mathrm{O}_{12}$ \\
\hline$[4]$ & 3 & $\times$ & $\times$ & $\times$ & $\times$ & 2 & $\times$ & 3 & $\mathrm{O}_{20}$ \\
\hline$[5]$ & $\times$ & $\times$ & $\times$ & $\times$ & 4 & $\times$ & $\times$ & 4 & $\mathrm{O}_{9}, \mathrm{O}_{13}, \mathrm{O}_{17}$ \\
\hline
\end{tabular}

Finally, we transform the reducts into the decision rules in the required format and presented in table 8 . For example, reduct number 1 is denoted as ' $1 \times \times \times \times \times$ $\times 1$ '. This leads to the following decision rule: IF $\mathrm{a}_{1}=1$, THEN the value of the decision attribute is 1 . Similarly, we can obtain the other decision rules also.

Table 8. Finalized Decision Rules

\begin{tabular}{|c|c|c|c|c|c|c|c|l|l|}
\hline Reduct & $\mathbf{a}_{1}$ & $a_{2}$ & $a_{3}$ & $a_{4}$ & $a_{5}$ & $a_{7}$ & $a_{8}$ & $\mathbf{d}$ & \multicolumn{1}{|c|}{ Supporting Objects } \\
\hline$[1]$ & 1 & $\mathrm{x}$ & $\times$ & $\times$ & $\times$ & $\times$ & $\mathrm{x}$ & 1 & $\mathrm{O}_{6}, \mathrm{O}_{10}, \mathrm{O}_{16}, \mathrm{O}_{21}$ \\
\hline$[2]$ & 2 & $\mathrm{x}$ & $\times$ & $\times$ & $\mathrm{x}$ & $\times$ & $\mathrm{x}$ & 2 & $\mathrm{O}_{5}$ \\
\hline$[3]$ & $\mathrm{x}$ & 4 & $\times$ & $\mathrm{x}$ & $\mathrm{x}$ & $\times$ & $\mathrm{x}$ & 3 & $\mathrm{O}_{20}$ \\
\hline$[4]$ & $\mathrm{x}$ & $\mathrm{x}$ & $\times$ & $\times$ & 4 & $\mathrm{x}$ & $\mathrm{x}$ & 4 & $\mathrm{O}_{9}, \mathrm{O}_{13}, \mathrm{O}_{17}$ \\
\hline
\end{tabular}

To validate the rules, they are tested against the testing dataset and their supporting count is marked. The first decision rule obtained in Table 8 is compared with each new object $\mathrm{O}_{23}, \mathrm{O} 24 \ldots \mathrm{O}_{30}$ from the testing data set. The number of objects that support the rule as well as that does not support the rule is obtained.

In rule 1 ,

Accuracy $=$

$$
\frac{\text { SupportedObjects }}{\text { Supported }+ \text { NonSupportedObjects }}=\frac{3}{3+1}=75 \%
$$

In rule 2 ,

Accuracy $=$

$$
\frac{\text { SupportedObjects }}{\text { Supported }+ \text { NonSupportedObjects }}=\frac{1}{1+0}=100 \%
$$

In rule 3 ,

Accuracy $=$

$$
\frac{\text { SupportedObjects }}{\text { Supported }+ \text { NonSupportedObjects }}=\frac{1}{1+0}=100 \%
$$

In rule 4 ,

Accuracy $=$

$$
\frac{\text { SupportedObjects }}{\text { Supported }+ \text { NonSupportedObjects }}=\frac{1}{1+2}=33 \%
$$


As the predefined threshold is at least $60 \%$, the rules 1, 2 and 3 are selected whereas rule 4 cannot be selected with sufficient confidence. Therefore, on increasing the threshold value, we can get better knowledge.

\section{EXPERIMENT AL RESULTS - A STUDY ON PADDY NUTRITION MANAGEMENT}

Nutrient management along with pest, disease, and weed control is a common management practice that increases nutrient use-efficiency and allows production of economic y ields. Knowledge of the amount and dynamics of nutrient removal is necessary to design fertilizer recommendations and timing of application. The study involves observing and analyzing historical data (20052012) of the KVK research station, Vellore, Tamilnadu. The 1100 data sets were checked for completeness and consistency. We removed distinct items in the data in order to avoid redundancy. Among the records, 592 crops other than paddy were removed from the dataset. In addition to this, 269 data with inadequate support were also removed. Also, 126 data were removed from the dataset with missing attribute values. In total, 975 data were removed from the dataset. The knowledge acquired from domain experts gave us an understanding of the historical data and essential attributes for nutrient management in paddy. The refined data set, resultant from preprocessing is subjected to rule formation in decision making.

The most common factors for paddy nutrition management includes the size of the field, growing season, crop establishment method, crop variety, growth duration of the rice variety from transplanting to harvest, total yield of variety in wet season, total yield of the field area, managing organic manures/straw/green manure, field location in low-ly ing area adjacent to lake or nearby river with flooding, texture of the soil and application of organic materials. We consider the size of the field is constant as three hectares and the $\mathrm{N}, \mathrm{P}, \mathrm{K}$ ratio can be man ipulated for other fields. Therefore, it is necessary to identify certain rules so that essential nutrient supplement can be identified at proper stage and also we can minimize the usage of unhealthy inorganic chemical fertilizers and thereby the financial burden. Literature and numerical values for nutrition management factors were collected and studied. These parameters form the basic attribute set for our analysis. The N,P,K supplement for paddy becomes our decision variable. The major attributes and their notations are given in table 9.

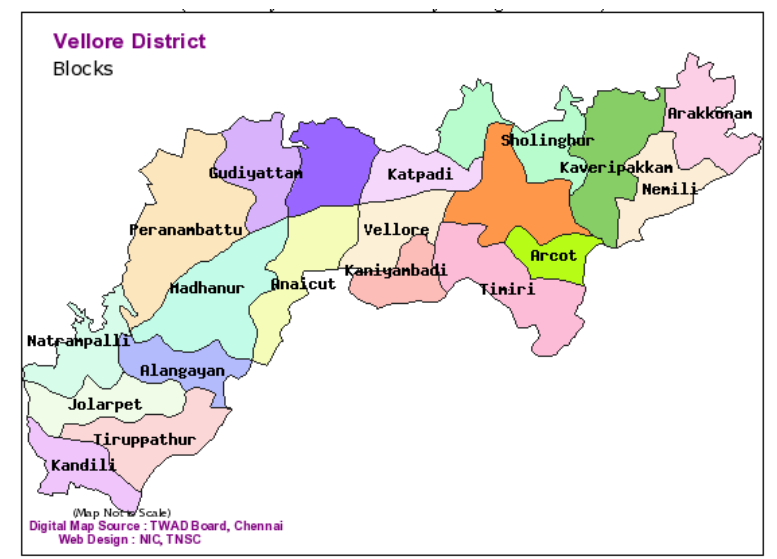

Fig 2. List of village blocks in vellore district [courtesy:http://tnmaps.tn.nic.in/district.php]

Table 9 . Notation Representation

\begin{tabular}{|l|c|c|}
\hline \multicolumn{1}{|c|}{ Management Measures } & Abbreviation & Notation \\
\hline Crop Variety & CV & $\mathrm{a}_{1}$ \\
\hline Growing Season & GS & $\mathrm{a}_{2}$ \\
\hline $\begin{array}{l}\text { Growth duration of the rice } \\
\text { variety from transplanting to harvest }\end{array}$ & GD & $\mathrm{a}_{3}$ \\
\hline Total Yield of field area & TYF & $\mathrm{a}_{4}$ \\
\hline $\begin{array}{l}\text { Managing Organic manures, } \\
\text { straw and green manure }\end{array}$ & OSGM & $\mathrm{a}_{5}$ \\
\hline Crop establishment Method & CEM & $\mathrm{a}_{6}$ \\
\hline Texture of the soil & TS & $\mathrm{a}_{7}$ \\
\hline Apply organic materials & AOM & $\mathrm{a}_{8}$ \\
\hline $\begin{array}{l}\text { Nitrogen (N), potassium (P), } \\
\text { phosphorous (K) supplies }\end{array}$ & NPK & $\mathrm{d}$ \\
\hline
\end{tabular}

Table 10. Coded Qualitative Attributes

\begin{tabular}{|c|c|c|c|c|}
\hline \multirow{2}{*}{ Attributes } & \multicolumn{4}{|c|}{ Codes } \\
\hline & 1 & 2 & 3 & 4 \\
\hline SZ & - & - & - & - \\
\hline GS & Wet Season & Dry Season & - & - \\
\hline CEM & Transplanting & Wet seeding & Dry seeding & - \\
\hline $\mathrm{CV}$ & Inbred & Hybrid & - & - \\
\hline GD & 90-99 days & 110-119 days & 100-109 days & 120-129 days \\
\hline TYF & $4-5 \mathrm{t} / \mathrm{ha}$ & $5-6 \mathrm{t} / \mathrm{ha}$ & $6-7 \mathrm{t} / \mathrm{ha}$ & $7-9 \mathrm{t} / \mathrm{ha}$ \\
\hline OGSM & $\begin{array}{l}\text { Remove all the above } \\
\text { ground crop biomass } \\
\text { from the field area }\end{array}$ & $\begin{array}{l}\text { Retain anchored crop } \\
\text { biomass (stubbles) } \\
\text { in the field }\end{array}$ & $\begin{array}{c}\text { Return straw from } \\
\text { the threshing pile } \\
\text { and spread over the } \\
\text { field before the next rice crop }\end{array}$ & $\begin{array}{l}\text { Use combine harvesting } \\
\text { machine with crop } \\
\text { residue retained in the field }\end{array}$ \\
\hline FL & Yes & No & - & - \\
\hline $\mathrm{TS}$ & Sticky clay & Sandy & - & - \\
\hline $\mathrm{AOM}$ & Yes & No & - & - \\
\hline
\end{tabular}


In particular, we randomly divided the 125 dataset into the training data set of 70 records $(55 \%)$ and the testing data set of 55 records $(58 \%)$. As we discussed in section III, Table 9 represents an information table with eight condition attributes and one decision attribute. Using the help of domain expertise we aim to derive rules from the training data to decide the amount of fertilizer usage. To discrete the information system, we need to translate values of decision and condition attributes from qualitative to quantitative form (yes,no,low, mediu m, high)

Table 11. Sample Training Dataset

\begin{tabular}{|c|c|c|c|c|c|c|c|c|c|}
\hline Objects & CV $\left(\mathrm{a}_{1}\right)$ & GS $\left(\mathrm{a}_{2}\right)$ & GD $\left(\mathrm{a}_{3}\right)$ & TYF $\left(\mathrm{a}_{4}\right)$ & OSGM $\left(\mathrm{a}_{5}\right)$ & CEM $\left(\mathrm{a}_{6}\right)$ & TS $\left(\mathrm{a}_{7}\right)$ & AOM $\left(\mathrm{a}_{8}\right)$ & N:P:K $(\mathrm{d})$ \\
\hline 1 & 1 & 1 & 1 & 1 & 1 & 1 & 1 & 1 & 4 \\
\hline 2 & 1 & 1 & 1 & 1 & 2 & 1 & 1 & 1 & 4 \\
\hline 3 & 1 & 1 & 1 & 2 & 1 & 1 & 1 & 1 & 5 \\
\hline 4 & 1 & 1 & 1 & 2 & 2 & 1 & 1 & 1 & 5 \\
\hline 5 & 1 & 1 & 1 & 3 & 1 & 1 & 1 & 1 & 8 \\
\hline 6 & 1 & 1 & 1 & 3 & 2 & 1 & 1 & 1 & 8 \\
\hline 7 & 1 & 1 & 1 & 1 & 1 & 1 & 2 & 1 & 4 \\
\hline 8 & 1 & 1 & 1 & 1 & 2 & 1 & 2 & 1 & 4 \\
\hline 9 & 1 & 1 & 1 & 2 & 1 & 1 & 2 & 1 & 5 \\
\hline 10 & 1 & 1 & 1 & 2 & 2 & 1 & 2 & 1 & 5 \\
\hline 11 & 1 & 1 & 1 & 3 & 1 & 1 & 2 & 1 & 8 \\
\hline 12 & 1 & 1 & 1 & 3 & 2 & 1 & 2 & 1 & 8 \\
\hline 13 & 1 & 1 & 2 & 1 & 1 & 1 & 1 & 1 & 1 \\
\hline
\end{tabular}

\section{A. Rule Generation}

Training dataset is employed to derive minimal subset of attributes (reduct) to ensure quality of classification and final rules are selected using expert knowledge. We have also removed identical rules and odd rules to avoid complexity. For each reduct the number of supporting objects is summarized. The candidate rules are generated based on supporting count. With a criterion of minimum two supporting count initially 43 candidate rules were formed later they were minimized to 16 (table 12) with domain knowledge.

Table 12. Decision Ruleset

\begin{tabular}{|c|c|c|c|c|}
\hline Rule & \multicolumn{2}{|r|}{ Description } & Support & $\begin{array}{l}\text { Non- } \\
\text { support }\end{array}$ \\
\hline \multirow{2}{*}{ [1] } & IF & Crop est ablishment method is transplanting and total yield of field is $4-5 \mathrm{t} / \mathrm{ha}$ & \multirow{2}{*}{23} & \multirow{2}{*}{0} \\
\hline & THEN & Nutrition supplement $\mathrm{N}: \mathrm{P}: \mathrm{K}$ is $13: 5: 0$ & & \\
\hline \multirow{2}{*}{ [2] } & IF & Crop establishment Method is transplanting and field is in low lying area & \multirow{2}{*}{15} & \multirow{2}{*}{0} \\
\hline & THEN & Nutrition supplement $\mathrm{N}: \mathrm{P}: \mathrm{K}$ is $47: 10: 00$ & & \\
\hline \multirow{2}{*}{ [3] } & IF & Crop est ablishment method is transplanting,total yield of field is $4-5 \mathrm{t} / \mathrm{ha}$ and field is in low lying area & \multirow{2}{*}{3} & \multirow{2}{*}{4} \\
\hline & THEN & Nutrition supplement $\mathrm{N}: \mathrm{P}: \mathrm{K}$ is $66: 15: 10$ & & \\
\hline \multirow{2}{*}{ [4] } & IF & total yield of field is $4-5 \mathrm{t} / \mathrm{h}$ a and field is not in low lying area & \multirow{2}{*}{5} & \multirow{2}{*}{3} \\
\hline & THEN & Nutrition supplement $\mathrm{N}: \mathrm{P}: \mathrm{K}$ is $66: 15: 10$ & & \\
\hline \multirow{2}{*}{ [5] } & IF & Crop establishment method is transplanting and total yield of field is 6-7 t/ha & \multirow{2}{*}{3} & \multirow{2}{*}{3} \\
\hline & THEN & Nutrition supplement $\mathrm{N}: \mathrm{P}: \mathrm{K}$ is $97: 20: 21$ & & \\
\hline \multirow{2}{*}{ [6] } & IF & Grow duration is 100-109 days, total yield of field is 5-6 t/ha and field is in low lying area & \multirow{2}{*}{5} & \multirow{2}{*}{5} \\
\hline & THEN & Nutrition supplement N:P:K is 97:20:21 & & \\
\hline \multirow{2}{*}{ [7] } & IF & Grow duration is $90-99$ days and growing season is dry & \multirow{2}{*}{4} & \multirow{2}{*}{9} \\
\hline & THEN & Nutrition supplement N:P:K is $106: 25: 32$ & & \\
\hline \multirow{2}{*}{ [8] } & IF & Growing season is dry, Crop est ablishment method is transplanting and field is not in low lying area & \multirow{2}{*}{4} & \multirow{2}{*}{3} \\
\hline & THEN & Nutrition supplement N:P:K is 100:25:30 & & \\
\hline \multirow{2}{*}{ [9] } & IF & Growing season is wet and field is in low lying area & \multirow{2}{*}{2} & \multirow{2}{*}{5} \\
\hline & THEN & Nutrition supplement N:P:K is 114:30:20 & & \\
\hline \multirow{2}{*}{ [10] } & IF & Total field yield is 5-6t/ha and field is not in low lying area & \multirow{2}{*}{2} & \multirow{2}{*}{6} \\
\hline & THEN & Nutrition supplement N:P:K is 114:30:20 & & \\
\hline \multirow{2}{*}{ [11] } & IF & Growing season is dry and growing duration is $110-119$ days & \multirow{2}{*}{1} & \multirow{2}{*}{5} \\
\hline & THEN & Nutrition supplement $\mathrm{N}: \mathrm{P}: \mathrm{K}$ is $114: 30: 20$ & & \\
\hline [12] & IF & Crop establishment method is dry seedling & 1 & 6 \\
\hline$[12]$ & THEN & Nutrition supplement $\mathrm{N}: \mathrm{P}: \mathrm{K}$ is $114: 30: 20$ & 1 & 0 \\
\hline
\end{tabular}




\begin{tabular}{|c|l|l|c|c|}
\hline \multirow{2}{*}{ Rule } & \multicolumn{2}{|c|}{ Description } & Support & $\begin{array}{c}\text { Non- } \\
\text { support }\end{array}$ \\
\hline \multirow{2}{*}[13]{} & IF & Growing duration is 100-109 days, total field yield is 6-7 t/ha and field is in lowlying area & \multirow{2}{*}{1} & \multirow{2}{*}{3} \\
\cline { 2 - 4 } & THEN & Nutrition supplement N:P:K is 114:30:20 & \multirow{2}{*}{3} & \multirow{2}{*}{6} \\
\hline \multirow{2}{*}[14]{} & IF & Growing season is wet and field is in low lying area & \multirow{2}{*}{3} & \multirow{2}{*}{5} \\
\cline { 2 - 4 } & THEN & Nutrition supplement N:P:K is 126:35:26 & \multirow{2}{*}{17} & \multirow{2}{*}{0} \\
\hline \multirow{2}{*}[15]{} & IF & Growing duration is 100-1 19 days, total field yield is 6-7 t/ha and field is not in low lying area & \\
\cline { 2 - 4 } & THEN & Nutrition supplement N:P:K is 126:35:26 & Nowing season is dry and growing duration is 100-109 days & \\
\hline \multirow{2}{*}[16]{} & IF & Gote* If straw is retained then P:K ratio is to be increased by 5-10 gms & \\
\cline { 2 - 4 } & THEN & Nutrition supplement N:P:K is 136:35:26 & \multicolumn{2}{|c|}{ Note } \\
\hline
\end{tabular}

Table 13.Candidate Rules

\begin{tabular}{|c|c|c|c|c|c|c|c|c|c|}
\hline Rules & CV & GS & GD & TYF & OSGM & CEM & TS & FL & NPK \\
\hline$[1]$ & $\mathrm{x}$ & $\mathrm{x}$ & $\mathrm{x}$ & 1 & $\mathrm{x}$ & 1 & $\mathrm{x}$ & $\mathrm{x}$ & 1 \\
\hline$[2]$ & $\mathrm{x}$ & $\mathrm{x}$ & $\mathrm{x}$ & 1 & $\mathrm{x}$ & $\mathrm{x}$ & $\mathrm{x}$ & 1 & 4 \\
\hline$[3]$ & $\mathrm{x}$ & $\mathrm{x}$ & $\mathrm{x}$ & 2 & $\mathrm{x}$ & 1 & $\mathrm{x}$ & 1 & 5 \\
\hline$[4]$ & $\mathrm{x}$ & $\mathrm{x}$ & $\mathrm{x}$ & 1 & $\mathrm{x}$ & $\mathrm{x}$ & $\mathrm{x}$ & 2 & 5 \\
\hline$[5]$ & $\mathrm{x}$ & $\mathrm{x}$ & $\mathrm{x}$ & 3 & $\mathrm{x}$ & 1 & $\mathrm{x}$ & $\mathrm{x}$ & 6 \\
\hline$[6]$ & $\mathrm{x}$ & $\mathrm{x}$ & 3 & 2 & $\mathrm{x}$ & $\mathrm{x}$ & $\mathrm{x}$ & 1 & 6 \\
\hline$[7]$ & $\mathrm{x}$ & 2 & 1 & $\mathrm{x}$ & $\mathrm{x}$ & $\mathrm{x}$ & $\mathrm{x}$ & $\mathrm{x}$ & 7 \\
\hline$[8]$ & $\mathrm{x}$ & 2 & $\mathrm{x}$ & $\mathrm{x}$ & $\mathrm{x}$ & 1 & $\mathrm{x}$ & 2 & 7 \\
\hline$[9]$ & $\mathrm{x}$ & 1 & $\mathrm{x}$ & $\mathrm{x}$ & $\mathrm{x}$ & $\mathrm{x}$ & $\mathrm{x}$ & 1 & 8 \\
\hline$[10]$ & $\mathrm{x}$ & $\mathrm{x}$ & $\mathrm{x}$ & 2 & $\mathrm{x}$ & $\mathrm{x}$ & $\mathrm{x}$ & 2 & 8 \\
\hline$[11]$ & $\mathrm{x}$ & 2 & 2 & $\mathrm{x}$ & $\mathrm{x}$ & $\mathrm{x}$ & $\mathrm{x}$ & $\mathrm{x}$ & 8 \\
\hline$[12]$ & $\mathrm{x}$ & $\mathrm{x}$ & $\mathrm{x}$ & $\mathrm{x}$ & $\mathrm{x}$ & 2 & $\mathrm{x}$ & $\mathrm{x}$ & 8 \\
\hline$[13]$ & $\mathrm{x}$ & $\mathrm{x}$ & 3 & 3 & $\mathrm{x}$ & $\mathrm{x}$ & $\mathrm{x}$ & 1 & 8 \\
\hline$[14]$ & $\mathrm{x}$ & 1 & $\mathrm{x}$ & $\mathrm{x}$ & $\mathrm{x}$ & $\mathrm{x}$ & $\mathrm{x}$ & 2 & 9 \\
\hline$[15]$ & $\mathrm{x}$ & $\mathrm{x}$ & 2 & 3 & $\mathrm{x}$ & $\mathrm{x}$ & $\mathrm{x}$ & 2 & 9 \\
\hline$[16]$ & $\mathrm{x}$ & 2 & 3 & $\mathrm{x}$ & $\mathrm{x}$ & $\mathrm{x}$ & $\mathrm{x}$ & $\mathrm{x}$ & 10 \\
\hline
\end{tabular}

\section{PERFORMANCE ANALYSIS}

To evaluate the performance, the proposed algorithm is validated against the real time data set of Vellore district. Two series of experiments were performed: one model on the original unreduced data and other on the reduced candidate rules. The rough based reduction algorithm selected five out of seven attributes. This reduced dataset (candidate rules) was reasonably information rich without redundant attributes. Using candidate rules (table 12) we examined the testing data set for accuracy, precision and recall measures. We observe that rules $1,2,3,4,5,6,7,8,16$ are above threshold value $40 \%$, other rules are discarded as it fails to reach threshold value. Two feature selection algorithms based on fuzzy and ANFIS versus the proposed algorithm have been applied for test and comparative measures (table 14). The results proved that our model avoids over fitting and produces sustainable results (table 15).

Table 14. Evaluation Measures

\begin{tabular}{|c|c|c|c|c|}
\hline Category & No of data set & Precision & Recall & Accuracy (\%) \\
\hline Rule 1 & 23 & 0.97 & 1.0 & 100 \\
\hline Rule 2 & 15 & 0.99 & 1.0 & 100 \\
\hline
\end{tabular}

\begin{tabular}{|c|c|c|c|c|}
\hline Rule 3 & 7 & 0.734 & 0.93 & 40 \\
\hline Rule 4 & 8 & 0.815 & 1.0 & 62 \\
\hline Rule 5 & 6 & 0.7335 & 0.75 & 50 \\
\hline Rule 6 & 10 & 0.75 & 0.72 & 50 \\
\hline Rule 7 & 13 & 0.73 & 0.723 & 42 \\
\hline Rule 8 & 7 & 0.834 & 0.733 & 57 \\
\hline Rule 9 & 7 & 0.576 & 0.51 & 28 \\
\hline Rule 10 & 8 & 0.671 & 0.61 & 33.33 \\
\hline Rule 11 & 6 & 0.376 & 0.26 & 16 \\
\hline Rule 12 & 7 & 0.341 & 0.29 & 16.67 \\
\hline Rule 13 & 4 & 0.33 & 0.31 & 16.67 \\
\hline Rule 14 & 9 & 0.65 & 0.68 & 33.33 \\
\hline Rule 15 & 8 & 0.71 & 0.59 & 33.33 \\
\hline Rule 16 & 17 & 0.99 & 1.00 & 100 \\
\hline
\end{tabular}

Table 15. Comparative Results Of Generated Reducts

\begin{tabular}{|c|c|c|c|}
\hline Algorithm & $\begin{array}{c}\text { No of Initial } \\
\text { Attributes }\end{array}$ & $\begin{array}{c}\text { Attributes after } \\
\text { reduction }\end{array}$ & $\begin{array}{c}\text { No of } \\
\text { Records }\end{array}$ \\
\hline Rough Set & 9 & 7 & 125 \\
\hline Fuzzy Rough Set & 9 & 4 & 125 \\
\hline Unsupervised & 9 & 9 & 125 \\
\hline
\end{tabular}




\section{CONCLUSION}

In Intensive cropping systems, knowledge of optimized fertilizer usage is important for developing future nutrient management strategies. This paper uses rough set theory as a useful data mining tool to depict the discovered knowledge in a direct way for nutrition management by inferring the appropriate physical conditions. This criterion is especially important in the agricultural domain because of the need for rule testability and verification by domain experts. The interesting measures such as support and confidence associated with the proposed model leads to minimized number of finalized decision rules with more accuracy. The experimental results proved to be feasible and efficient after testing with real time dataset that appropriately represents expert's decision processes. In Future, Rough set model can be hybridized with fuzzy, genetic, entropy measures to solve multi attribute based decision making.

\section{REFERENCES}

[1] Z. Pawlak, "Rough Sets: Theoretical Aspects of Reasoning about Data", Kluwer Academic Publishers, Dordrecht, The Netherlands, 1991 .

[2] Dr. K.V. Rao , "Site-Specific Integrated Nutrient Management for Sustainable Rice Production and Growth", from internet,2012,http://www.rkmp.co.in

[3] M. Magnani, "Technical Report on Rough Set Theory for Knowledge Discovery in Data Bases", from internet, 2003.

[4] P.S. Swathi Lekshmi,K Chandrakandan and N Balasubramani, "Yield Gap Analy sis among Rice Growers in North Eastern Zone of Tamil Nadu",Agricultural Situation in India, vol. 63 no. 2,pp 729-773, 2006,

[5] Z.Pawlak , "Rough Sets", International Journal of Computer and Information Sciences, vol 11, no. 5, pp 341356, 1982.

[6] T. Y. Lin, Y. Y. Yao and L. A. Zadeh, "Data Mining, Rough Sets and Granular Computing", Physica- Verlag, pp.102-124, 2002.

[7] Z. Pawlak and A.Skowron, "Rudiments of rough sets", Information Sciences, Elsevier,vol.177 ,no. 1,pp 3-27, 2007.

[8] Qiang Shen and Alexios Chouchoulas, "Rough Set - Based Dimensionality Reduction for Supervised and Unsupervised Learning", International Journal of Applied Mathematics and Computer Sciences, vol. 11, no. 3, pp 583-601, 2001.

[9] Jiye Li and Nick Cercone, "Discovering and Ranking Important Rules" ,KDM Workshop, 2006, Waterloo, Canada, Oct 30-31,pp.152-171

[10] S Joseph, PP Ouseph, "Assessment of nutrients using multivariate statistical techniques in estuarine systems and its management implications: a case study from Cochin Estuary, India", Water and Environment Journal,vol 24, no. 2, pp 126-132, 2010.

[11] N.Xiong, and L.Litz, " Reduction of fuzzy control rules by means of premise learning - method and case study", Fuzzy Sets and Systems, vol.132,no.2,pp217-231.2002.

[12] J.Han , X.Hu and T.Y. Lin, "Feature Subset Selection Based on RelativeDependency between Attributes" , Rough Sets and Current Trends in Computing: $4^{\text {th }}$ International Conference, RSCTC Uppsala,Sweden,June15,pp.176-185,2004.
[13] A.Kangaiammal, R.Silambannan, C.Senthamarai,M.V. Srinath, "Student Learning Ability Assessment using Rough Set and Data Mining Approaches", IJMECS vol. 5, no. 5, June 2013

[14] Ali Khazaee, "Heart Beat Classification Using Particle Swarm Optimization", IJISA,vol. 5, no. 6, May 2013

[15] CN. Mac Parthaláin,., R.Jensen and Q.Shen, “Fuzzy entropy-assisted fuzzy rough feature selection", Proceedings of the 15th International Conference on FuzzySystems,pp423-430,2006

[16] M.G. Smith and L.Bull , "Feature construction and selection using genetic programming and a genetic algorithm", Proceedings of the 6th European Conference on Genetic Programming , EuroGP Essex,UK,April,vol 14-16,pp229-237,2003

[17] X.Y. Wang, J.Yang, X.Teng , W.Xia, Wand R.Jensen, "Feature Selection based on Rough Sets and ParticleSwarmOptimization", PatternRecognitionLetters, vo 1. 28,no. 4,pp 459-471, 2004,

[18] P. Mitra, C.A.Murthy and S.K Pal, "Unsupervised feature selection using feature similarity", IEEE Transactions on Pattern Analysis and Machine Intelligence, Washington, DC, USA ,vol 24,pp 301-324, 2004,

[19] Liu , Huan and Hiroshi Motoda, "Computational methods of feature selection". Chapman and Hall/CRC,2007.

[20] K.Zuhtuogullari, N.Allahverdi and N.Arikan, "Genetic algorithm and rough sets based hybrid approach for reduction of the input attributes in medical systems",International Journal of Innovative Com puting, Information and control,vol.9,no.7,pp 30153037,2013

[21] X.Pan and S. Zhang, " Remote sensing image feature selection based on á-torrent rough set theory" , 7th International Conference on Fuzzy Systems and Knowledge Discovery, Yantai, Shandong,China,pp.10341038,August 2010

[22] C.C Hsiao, , Yi-Wei Ku „ “ A predictor from numerical data based on fuzzy sets and rough sets", $3 r d$ International Workshop on Advanced Computational Intelligence, IWACI,Suzhou, China, August 2527, pp.139-144,2010.

[23] N.Ishii, Y.Morioka, H.Kimura,Y.Bao, "Classification by multiple reducts-KNN with confidence", 11th International Conference on Intelligent Data Engineering and Automated Learning,Paisley,UnitedKingdom,,vol 6283,pp94-101, September1-3,2010

[24] N.M. Parthaláin, R.Jensen , Q.Shen, “ Finding fuzzyrough reducts with fuzzy entropy", IEEE international conference on fuzzy systems, Hong Kong, China, pp.12821288, June 1-6 2008

[25] A.Abraham, H.Liu, "Swarm Intelligence based rough set reduction scheme for support vector machines", IEEE International Conference on Intelligence and Security Informatics,Taipei, Taiwan, pp. 200-202, June 17-20 2008

\section{Authors' Profiles}

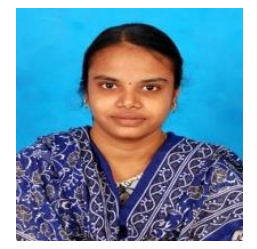

K.Lavanya is working as Assistant Professor in the school of computing science and engineering at VIT University, Vellore, Tamilnadu, India. Her area of interests includes Distributed Systems, Artificial Intelligence, High Performance computing and Intelligent computing. She is currently doing her research work in the interdisciplinary field of agriculture, computer science and tries to solve out the problems in agriculture farming practices such as marketing, 
crop management activities, disease control etc., using machine learning techniques.

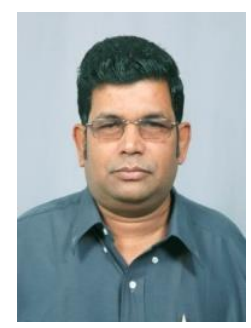

Dr. N.ChS.N.Iyengar (1961) is currently Senior Professor at the School of Computing Science and Engineering at VIT University, Vellore-632014, Tamil Nadu, India. His research interests include Agent-Based Distributed Secure Computing, Intelligent Computing, Network Security, Secured Cloud Computing and Fluid Dynamics. He authored several textbooks and had nearly 167 research publications in reputed peer reviewed international journals. He served as PCM/reviewer for many international conferences. He is Editor in Chief of International Journal of Software Engineering and Applications( IJSEA) of AIRCC, Guest Editor for Special Issue on Cloud Computing and Services of International Journal of Communications, Network and System Sciences and Editorial Board member for International Journals like IJConvC (Inderscience -China)etc

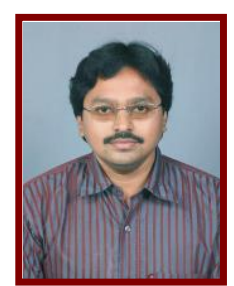

M. A. Saleem Durai received the MCA from Bharathidasan University, Tiruchirapalli, Tamilnadu, India in 1998; M. Phil. from from Madurai Kamaraj University, India in 2008 and pursuing his $\mathrm{PhD}$ at VIT University Vellore. $\mathrm{He}$ is an Associate Professor in the School of Computing Sciences and Engineering at VIT University, Vellore, Tamilnadu, India. He has authored many International and National journal papers to his credit. His research interests include data mining, fuzzy logic, cloud computing and rough sets. Mr. Saleem Durai is associated with many professional bodies CSI and IEEE.

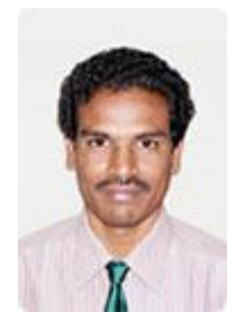

Dr.T.Raguchander is working as Professor in the Department of plant Pathology, Tamilnadu Agricultural University, Coimbatore, 641 003, India. His area of specialization are phytotoxin inactivation by microbes, plant growth promoting rhizobacteria mediated resistance, development of bioformulation for the management of plant disease and Molecular Plant Pathology. He obtained 14 externally funded schemes from several National and International firms. He has published 80 research papers in International journals, 100 research papers in National journals and 4 books. His Citation index is 561 till 2012 and citation index in scopus is 12.5 . He is currently interested in interdisciplinary studies to enhance the portability of agricultural studies especially in plant disease management and betterment of farming community by user friendly technology deliverable media.

How to cite this paper: K. Lavanya, N.Ch.S.N. Iy engar, M.A. Saleem Durai, T. Raguchander,"Rough Set Model for Nutrition Management in Site Specific Rice Growing Areas", International Journal of Intelligent Systems and Applications(IJISA), vol.6, no.10, pp.77-86, 2014. DOI: 10.5815/ijisa.2014.10.10 